\title{
Shaping Teachers' Perceptions of their role in the Digital age Through Participation in an Online PBL-based Course
}

\author{
Orit Avidov-Ungar ${ }^{1,2}$ and Dina Tsybulsky ${ }^{3}$ \\ ${ }^{1}$ Achva Academic College, Shikmim, Israel \\ ${ }^{2}$ The Open University, Raa'nana, Israel \\ ${ }^{3}$ Technion - Israel Institute of Technology, Haifa, Israel \\ Both authors contributed equally to this publication \\ avidovo@achva.ac.il \\ oritav65@gmail.com
}

\begin{abstract}
Our research traced significant learning experiences of teachers enrolled in a Master's degree program in teacher education, in an attempt to understand how participation in an online course that employs the project-based learning (PBL) approach influenced their perceptions of the teachers' role in the digital age. Data was collected from 2014 to 2016 using: (a) a questionnaire gathering learners' personal and demographic details $(n=55)$ and (b) reflective reports on the learners' learning experiences in the course $(n=105)$. Content analysis of the data revealed that participants considered personal, pedagogic, and social aspects important in terms of the learning experience and this also informed their role perception as teachers in the digital age. Similarly, exposure to the PBL approach via an online framework directly influenced participants' learning experiences and role perception. The findings indicate that teachers should be given access to a learning experience combining online learning and teaching practice to allow them to form their role perception as digital-age teachers. Practical implications of the research relate to teachers' socialization in the digital age.
\end{abstract}

\section{Introduction}

We now live in a digital era. One of the changes that has taken place during the transition to this era which has strongly influenced education systems is the development from Information Technology (IT) computer systems to Information and Communication Technology (ICT) computer systems. This has significantly improved communication and interpersonal transferring of information and, consequently, has greatly influenced learning-teaching processes and practices. As a result of radical changes in the surrounding reality, people have begun to refer to themselves as inforgs (information organisms) acting within an infosphere (Floridi, 2014). Thus, one's self-perceptions as well as relationships-with self, others, and the environment-- have been fundamentally altered (Levin and Tsybulsky, 2017; Floridi, 2014; Tsybulsky and Levin, 2019).

The adaptation of teacher education and professional development programmes to the digital era should take into account the learner's worldview and its implications vis-à-vis education and society in general (Tsybulsky and Levin, 2019; Tsybulsky and Muchnik-Rozanov, 2021). Aligned with this approach, the present study developed from a conceptual framework that sees teachers' professional development as a process of socialization, which aims to prepare teachers to perform in the field of education in a manner suitable to the digital era. To attain this goal, however, the relevant programmes must provide ample opportunity for significant practice and experiences in the ICT context.

This new era calls for digital acculturation, which must include learning, teaching, and evaluation processes in which the routine use of ICT is an inseparable part of teachers' domains, rather than an external auxiliary tool. Teachers who perceive technology as a constructive and integral part of pedagogical processes and whose teaching is grounded in a digital worldview can help create the change necessary to advance the entire education system. In this sense, teachers' role perception encompasses each individual's entire set of beliefs about the role and its effects on both oneself and others (Ben-Peretz, Mendelson and Kron, 2003).

One of the experiences that allows for the assimilation of digital culture in teachers' professional development processes is learning through participation in an online course (Baldwin, Ching and Hsu, 2018; Ching, Hsu and Baldwin, 2017; Kleen and Soule, 2010). Additionally, in recent years, the project-based learning (PBL) approach has gained increased recognition as a meaningful student-centred, inquiry-based learning method, that can be conducted as a collaborative activity and hence is suitable for developing students' $21^{\text {st }}$ century skills (Chu, Reynolds, Tavares, Notari and Lee, 2016; Häkkinen, et al., 2017; Tsybulsky, et al., 2020). Very few studies, to 
date, have focused on online distant learning that includes the use of the PBL approach; the majority of distancelearning courses offered online rely on traditional learning-teaching methods ( $\mathrm{Ni}, 2013$ ).

It is in this context that we decided to conduct research among practicing teachers studying for a Master's degree in a teacher-training college. The degree programme included an online course that employed the PBL approach, intended to foster participants' professional development. In order to understand whether and how the teachers' perceptions were shaped and structured by this experience, we examined their reflections on their experiences and perceptions as they evolved throughout the course. It should be noted that the participant population in this study was very unique: they were both in-service teachers working in schools, while simultaneously studying for a Master's degree in Education in an academic institution. In other words, these teachers "wore two different hats." In one role, they were acting as teachers of pupils in school, while in their other role (specifically, one day a week on their free day from school), they were graduate students in an academic institution.

\subsection{Teachers' perceptions in the digital age}

The study of teachers' perceptions and beliefs has recently become a priority for educational researchers (Fives and Buehl, 2008). Analysis of teachers' perceptions can clarify educational practices. Teachers' perceptions guide instructional decisions, influence classroom management, and serve as a lens for understanding classroom events,(e.g., Jones and Carter, 2007; Luft and Roehrig, 2007; Prestridge, 2017. A substantial body of research has been generated in this domain (e.g., Jones and Carter, 2007), leading to four principal conclusions regarding teachers' perceptions. Perceptions are multidimensional and complex (Hofer, 2001; Stahl and Bromme, 2007); they affect teachers' practices (Brownlee and Berthelsen, 2006, 2008; Marra, 2005); and they are context-bound (Fives and Buehl, 2008, 2010). Instruction and short-term interventions designed to promote either conceptual change, reflection, or examination of personal beliefs and perceptions have a positive effect on teachers' beliefs and classroom practices (Mason, 2010).

In the context of the digital age, a study by Tsybulsky and Levin (2019) indicated that teachers' perceptions concerning their place and role vis-à-vis the digital age can be classified according to the three types, namely, the outside observers, the circumspect participants, and the conscientious participants. Conscientious participants were those teachers who considered themselves an integral part of the digital society. Not only are conscientious participants aware of the existence of the digital society, they also feel that they are a vital part of it. In this sense, they can be considered "digital citizens." Accordingly, digital citizenship includes three components: an objective and realistic view of the surrounding environment with an awareness of the revolutionary changes taking place in contemporary digital society; a perception of interpersonal interactions as involving digital communication and sharing with others; and a subjective self-perception which includes awareness of one's role vis-à-vis one's surroundings, and an understanding that performing this role requires digital acculturation (Tsybulsky and Levin, 2019). There has been a growing interest in the professional literature in the notion of digital citizenship, with attempts to define its components, as well as its effects on teachers operating in a digital environment (Choi, Glassman and Cristol, 2017). Building on these previous findings, the research described in this article examined whether and how participation (as a Master's degree student) in an online course using the PBL approach could provide a meaningful experience, one that could help shape teachers' perceptions of their professional role from the perspective of digital citizens in the digital age.

\subsection{Learning in an online course}

An online course constitutes a unique learning environment that contains relevant and varied informative contents, activities, and assignments that require a degree of initiative and creativity (Khan, et al., 2017). The format requires learners to participate in forums, communicate via email, and use links to knowledge banks and other relevant sites (Baldwin, Ching and Hsu, 2018). The premise of an online course is that higher-order learning is best supported in a community of learners engaged in critical reflection and discourse (Garrison and Cleveland-Innes, 2005; Hill, Song, and West, 2009; Garrison, Anderson, and Archer, 1999; Sung and Mayer, 2012). Garrison, Anderson, and Archer (2001) proposed a community-of-inquiry model of online learning. This conceptual framework was based on the idea that the success of a community of learners depends on interactions between the instructor and the content, among the students, and between students and the instructor. The manifestation of these interactions requires cognitive presence, social presence, teaching presence, as well as emotional presence (Majeski, Stover, and Valais, 2018). 
Hussein-Faraj, Barak and Dori (2012) found that students studying online enjoyed more positive learning experiences than did students studying in traditional frameworks using traditional methods. Students noted the importance of convenient and easily accessible communication, and the numerous possible ways to illustrate and demonstrate abstract concepts in online learning. Other contemporary studies have stressed the contribution of the online lecturer to students' sense of satisfaction regarding the learning. A positive correlation was found between the students' perception of the lecturer's commitment and high quality of teaching, the level of students' achievements, and participants' general satisfaction from the online learning experience (Xiao and Wilkins, 2015). A study by Naresha, Reddyb and Pricildac (2016) listed several levels of learners' awareness in an online course, examining the extent of the students' acceptance and adoption of the digital learning environment. It was clear that the digital learning courses provided global exposure and helped learners enjoy the experience of distance learning in real time. Parkes, Stein and Reading (2015) discussed the issue of the students' readiness to operate in an environment of academic institutions that is characterised by digital learning. The current generation of learners has been called digital natives (Prensky, 2009), in reference to their comfort and familiarity with digital technology. Nevertheless, the question remains relevant: To what extent are the students prepared for functioning and utilising the online environment in their academic studies? One way to address this issue is by offering online distance-learning courses that implement the PBL approach.

\subsubsection{The PBL approach}

Research has shown that online learning combined with a PBL approach significantly advances academic learning, both from the perspective of the learner and also with regard to the process (Barak and Watted, 2017; Taradi, et al., 2005). Learning of this kind provides the learner, the lecturer, the academic institute and the society as a whole with a significant contribution: they receive high-quality learning products that are effective and more appropriate for their needs. Nevertheless, online learning combined with PBL involves addressing various requirements pertaining to pedagogical and technological content, which need to be predefined and necessitate the compliance all those involved in the process: the instructor, the learner and the academic institute (Taradi, et al., 2005). Participation in an online course combined with practice according to the PBL approach has the potential to provide learners with meaningful experiences that will shape and develop their self-perception as digital citizens and informed teachers.

\subsection{Experiences and their importance in the learning process}

The theory of experiential learning, proposed by Kolb (1983), sees learning as a process in which knowledge is constructed through active experience. The cycle of experiential learning constitutes a key component in Kolb's theory (Kolb, 1983; Kolb and Kolb, 2005) and it includes four interrelated stages: concrete experience, reflective observation, abstract conceptualization, and active examination of the use of the new concepts in new situations. Experiential learning in teachers' professional development has focused on the teachers' experiences as they develop their skills in the classroom: experimenting, reflecting, and adapting new theories, practices, and content, to which they were introduced in a professional context (Girvan, Conneely and Tangney, 2016). In the current study, we applied Kolb's theory of experiential learning and the concept of the circle of experiential learning to explore teachers' experience of learning in an online course using the PBL approach. In our comprehensive process of observation, we first considered participants' concrete experiences while participating in the online course, and then focused on their reflections, their construction of new educational views and perceptions, and concluded with an examination of their active implementation and use of the new concepts in new situations, namely the designing of their educational projects.

Research conducted very recently by Tsybulsky, et al. (2020) examined the content and quality of developing experiences of student-teachers, when studying pedagogic courses according to the PBL approach. This research indicated, among other things, that the trial experience with the PBL approach provided a positive (introspective, social and cognitive) learning experience that produced significant learning and the professional development of student-teachers. Another study by Tsybulsky and Oz (2019) indicated that the significant experiences of student-teachers when leading PBL in elementary-school classes shaped their educational attitudes and practices. On the basis of these studies, the assumption underlying the current study is that implementing the PBL approach to the distance-learning platform and format would similarly render significant experiences that shape teachers' educational views, including their perception of their role as teachers in the digital age.

The present study aimed to trace significant learning experiences of teachers, studying for a Master's degree in a teacher-training college, in order to understand how the experience of learning in an online course using the PBL approach shaped their role-perceptions as teachers in the digital era. This distinct combination of distance 
learning with the PBL approach affords a unique opportunity for students and instructors alike; moreover, it constitutes a promising framework for examining teachers' role perception in the digital age.

With this goal in mind, the following research questions were formulated:

What were the main experiences of teachers while participating in an online course using the PBL approach? Did the teachers' learning experiences in the online course using the PBL approach enable them to form a perception of teachers' role in the digital era, and if so, how?

\section{Methodology}

\subsection{The method}

The research followed a hermeneutic phenomenological approach (van Manen, 1990, 2014). An underlying assumption of this approach is that the information that the study seeks to reveal can be found in the meanings that participants attribute to their experiences (van Manen, 1990). A phenomenological study focuses on the common meaning that several individuals attribute to their experience of a phenomenon, in other words, the common denominator of participants' perceptions regarding their experience of a phenomenon (Creswell and Poth, 2016). The phenomenological approach is a valuable method for examining participants' learning experiences as it provides the researcher insight into the participants' perspectives regarding the phenomenon under study (Tsybulsky, et al., 2020).

\subsection{The context and the research population}

The research population comprised 55 practicing teachers who between 2014-2016 had enrolled and participated in an annual course that was offered as part of a Master's degree programme in education (with a focus on management of educational systems). In this context, it is again important to remember that the participants were both in-service teachers working in schools, while simultaneously studying for a Master's degree in Education in an academic institution. In the context of this study, we refer to the participants as students in an academic institution, as there is no mention of their work as teachers. Although, in their reflective journals the participants occasionally referred to their work as teachers, their status in the context of this research remains that of graduate students.

The course was delivered as an online course using a Modular Object-Oriented Dynamic Learning environment (referred to as the MOODLE platform). This is an online, asynchronous platform, which course participants could use to complete their assignments, to maintain contact with the lecturer and with fellow students in the course, and to access the information that the lecturer sought to convey to students. The platform also displays the individual student's progress in the course. As it is an asynchronous platform, students could advance through the course at their own individual case, while maintaining a dialogue with the lecturer, and interacting with fellow students. Furthermore, on the MOODLE site, a forum was established for posting questions and responses, both between the students and the lecturer, as well as among the students in the course. No other social network platform, such as Facebook or WhatsApp, was used; all communication took place within the course's domain on the MOODLE platform.

The subject of the course was organisational learning. Course assignments varied and alternately required individual and group work. At the end of the period of online learning, three face-to-face meetings were held, during which students presented the products of their project. The goal of the course as defined in the syllabus was 'to help students understand the significance of processes of organisational learning and the ways to transform an organisation into a learning organisation. The course is delivered within a framework for distance learning and calls for individual and group study. The course encourages active learning so as to create a learning experience that encompasses practical and applicable aspects.

The students were assigned a group project as part of the course, namely, to construct a programme for promoting an organisational learning culture in the school; their proposal should specify the processes, means and the manner in which the proposed change would be assimilated among the school's teachers. The students worked on this assignment in groups of 3-5 students. The intermediate products included an interview with a staff member who held a leading role in the organisation, a joint presentation to introducing the main concept and its realisation, and presentation of the project before their peers, who also participated in evaluating the product and provided verbal feedback online. 
During the period of the study, 2014-2016, the course was offered three times: In the 2014 course, 19 students participated; in 2015 there were 17 participants; and in 2016, 19 students. Among all 55 participants, the majority were women (90\%), most were elementary-school teachers (70\%) and the remainder taught in secondary schools. Most of the participants (86\%) reported that they had medium-high mastery of computer skills and only a few (14\%) reported low mastery; however, it should be noted that none of them reported high mastery of computer skills. Participants' ages ranged between 30 and 50 years, with a mean age of 39 . All of the participants lived within a $40 \mathrm{~km}$ radius from the academic institution in which they were studying; nevertheless, this factor was not important to the learning, as all of the course was held in an online asynchronous environment. Participants' teaching experience ranged between 5 and 18 years, with a mean of 12 years of experience. A relatively small proportion of the students had previous experience in online learning, whereas for the others, this was their first time studying in this format.

The participants were informed about the research goals and procedure and indicated their willingness to participate, by completing a written informed consent form. The study was approved by the University's Ethical Committee.

\subsection{The research instruments}

The two main research instruments employed were a questionnaire and reflective reports. The questionnaire served to collect the data regarding participants' background variables, i.e., their gender, age, years of teaching experience, the class levels that they taught (elementary or secondary), prior computer skills, and past participation (or lack thereof) in an online course. All of the students ( $n=55$ ) completed the questionnaire. In the reflective reports, the participants recorded their reflections about their experiences in the course. They were asked to consider their learning experience throughout the course, in a free manner, without any particular instructions to guide them. Students were asked to record their reflections twice during the course, in the middle of the course and at its conclusion. In total, 105 reflective reports were reviewed. Five students completed this assignment only once. It should be noted that the reflective reports constitute a common manner for collecting data in phenomenological studies, as they afford participants to reflect retrospectively on their experiences (van Manen, 1990, 2014).

\subsection{Data analysis}

The data were analyzed using the phenomenological data analysis method, which provides an understanding of how participants experienced the phenomenon (Moustakas, 1994). The unit of analysis that was employed was that of teachers' expressions, defined as a clause or clause complexes (a number of clauses). Using the definition of clause as put forth by Halliday and Matthiessen (2013), clause is a unit of language that contains at least one subject and one predicate. The analysis procedure included several stages. The first stage involved coding of the data, whereby text transcripts were scanned for recurring "significant statements" (Moustakas, 1994) and expressions regarding the learning process that the participants experienced. Descriptions of experiences, i.e., participants' thoughts, feelings, and emotions, were identified by the appearance of clauses such as "I felt," "I experienced," and "I thought." An examination of the expressions used in such clauses enabled us to cluster them into "core themes" (Moustakas, 1994). In the final stage of the analysis, the significant statements and themes were incorporated into a narrative expression of the results, that is, a 'textual description' of what the participants had experienced, based on their descriptions (Moustakas, 1994).

The validity of the study was ascertained by conducting a thorough examination of data at the different analytic stages, so that at each stage the researchers were able to reconfirm that the findings of the previous stage were grounded in the data. Each of the researchers analysed the data individually and according to their best understanding and knowledge of the studied field. Next, a brainstorming session between the two researchers was held, which included a discussion of each researcher's findings and their correspondence to the research questions. In cases of initial disagreement, additional discussion ensued until a joint decision could be reached regarding the assignment of the narrative texts to particular categories. 


\section{Findings}

The findings are presented in two sections in line with our research questions.

\subsection{The experiences of teachers participating in an online course using the PBL approach}

In general, most of the teachers learning in the online course reported that they enjoyed a positive, interesting, and challenging experience that enriched and deepened their understanding of the studied contents and reinforced the creative aspect in the learning process. The combination between independent work and team work strengthened the learners' sense of individual and group responsibility and increased their sense of cohesion as a group. The teachers used several principal expressions to describe their learning in the course including: 'a challenging experience', 'practical contents', 'varied teaching methods', 'comfortable distance learning' and 'peer learning'. Nevertheless, a few of them reported negative learning experiences and even mentioned several difficulties involved in the course framework such as a heavy load, difficulty in managing the learning from a distance without regular face-to-face meetings, and difficulty working with the staff from a distance.

A more focused analysis of the findings revealed that the learners' addressed three main aspects (a) the personal aspect, i.e., their individual learning experience in the course; (b) the social aspect, i.e., relationships that were formed between peers and with the lecturer; (c) the pedagogic aspect, i.e., teaching methods and the learning process of the course. In each of these aspects, it was possible to discern both positive experiences of the learners which were viewed as the advantages of online learning, and negative experiences which were associated with the difficulties involved in online learning. A detailed description of the three aspects follows.

\subsubsection{The personal aspect of experiences of teachers learning in the online course}

As noted, this aspect included the learners' observations regarding their learning experience. The participants related especially to their pleasure during the learning, the speed, and quality of feedback during the course, the study load, the options within the course, the manner in which they presented assignments, and their general satisfaction with the course. The positive experiences were mainly associated with a rich variety of content knowledge, the comfort and ease of the timetable for performance of assignments, the sense of enjoyment increasing their motivation, the ability to choose methods and tools, the availability of subject materials, and the speedy response of the lecturer. Thus, for example one of the teachers noted:

I experienced learning that did not involve a blackboard and chalk. It was a different kind of experience, including active learning that requires higher-order thinking in all areas - from joining a work group that motivated me to learn, through the integration of technological tools. Also reading articles in English, gaining insights, the experience of personal learning achieved together through team work.

Negative experiences were mainly associated with the study load imposed by course assignments, not all the assignments were seen as relevant to the course subject, and there was a sense of deficient interpersonal communication with members of the group in order to perform the assignments. Thus, for example, one of the participants remarked: 'The course was very intensive; there was a lot of material covered in a short period of time. The integration of technology did not always address the need'.

According to the teachers' reports, they found these experiences mainly help with self-discipline and [in providing] exposure to a variety of sources of information. It is important for us to internalise these insights as central leading figures in the organisational systems in the digital era.

\subsubsection{The social aspect of the experience of teachers studying in the online course}

As noted, the social aspect of the experiences reported by the participants pertained to the relationships they developed with their peers.

The participants emphasised the unique experience of working as a team with peers, but from a distance. They noted that while this connection offered a different type of interaction, particularly because the experience was new to them, it was also so foreign to them that they often found that they needed to communicate by telephone in order to "bridge" the physical distance between them. They also reported a strengthening of their sense of responsibility for completing the assignments, due to the collective nature of the group course work. The collaboration created a positive and challenging learning experience. Thus, for example some of them noted: 
'independent work alongside work in a team reinforced personal and group responsibility', 'the performance of personal assignments led to the performance of group assignments', 'I have responsibility for others as well'.

Some of the participants also testified that the work relationships that were forged and developed during the course extended beyond the framework of the course. Thus, for example, one of the participants remarked:

Forging relationships with my peers in order to complete assignments created a challenge, but also provided an opportunity for us to get to know each other; we also began to help by each other complete tasks that we were given in the school. We became colleagues in the teaching profession.

The difficulties noted were related mainly to the assignment to one team rather than another. For example, one of the course participants said:

As with anything new and different, there were fears concerning the structure of the course and its performance. Already at the first meeting, I did not find myself assigned to the group I wanted, but fairly quickly I understood that I had to alter my thinking and accept that I was not the one to choose.

Other difficulties mentioned were related to the framework of distance learning and its effect on interpersonal and group interactions. One of the participants remarked: 'The need to fit into a learning group when you don't know any of the participants or your abilities makes things very difficult'.

\subsubsection{The pedagogic aspect of the experiences of the teachers studying the online course}

As mentioned above, this aspect was identified when the participants' reports referred to the learning experience, emphasising the processes, methods, and tools the lecturer employed to bring the learners to optimal achievements. Additional components of the pedagogic aspect were related to the instructor's performance, specifically, providing reflective feedback on the learners' progress and evaluating their achievements in the knowledge domain. participants also noted the combination of varied teaching methods, the attractive and challenging presentation of materials and the perception of the course lecturer as a model for imitation on the subject of integration of technological tools in teaching.

Positive experiences were associated mainly with the ability to learn and apply new teaching aids, personally experiencing the construction of a learning unit using technological means, self-enrichment by learning various materials on the course subject, and working together within a collaborative group. For example, one of the teachers noted,

There was a sense of openness and an intellectual experience when constructing a learning unit with the help of technological means. [I] understood that organisational learning [the subject of the course] is useful not only for the school but also in daily life.

The negative experiences were mainly associated with the difficulty of learning online without regular meetings, the lack of face-to-face feedback, lack of explanation by the lecturer concerning materials presented in graphs and tables. Some of the participants thought that it was not always possible to express themselves. Working in groups made performance difficult, especially in the context of a lack of mastery of technological tools and the sense that not everything was relevant for their teaching. This was expressed by one of the teachers thus:

Interaction at a distance makes things difficult. There was a lack of visibility; the presentations were full of graphs and tables with no face-to-face explanations. This makes learning very difficult and reduces the pleasant experience of the course. Also, I don't always understand what I can do with it [what is learned] as a teacher in the classroom.

\subsection{The way the online course experience using the PBL approach shaped participants' perception of their role as teachers in the digital age}

This section of the findings relates to the role perception of the teachers participating in the online course and the relevancy of the learning and materials in the course to their current and future role as teachers in the digital era.

A more focused analysis of the reflections reported by the teachers at the end of the course identified three aspects of their role perception as teachers in the digital era: (1) the personal aspect - the teacher's selfperceptions regarding their own professional functioning and their role when working both in the virtual realm and face-to-face with others; (2) the social aspect-participants' perceptions of a teacher's role when engaging 
in team work and professional collaboration; and (3) the pedagogic aspect -participants' views regarding a teacher's educational practices when working in the online environment and collaborating according to the PBL.

\subsubsection{The personal aspect of the teachers' role perception as shaped by the online course experience}

The online course experience shaped teacher's personal self-perception regarding their own professional functioning and role in the following ways. First, the experience of improving their own methods of online learning helped them hone their teaching methods in the virtual space. Likewise, as their fears concerning the use of technology tools were alleviated, they came to perceive the ICT tools as more user-friendly. Second, they came to perceive professional development as a continuous, multidimensional process, a perspective that is in line with contemporary approaches. Finally, having gained valuable experience in online learning not only helped shape and reinforce their motivation, but also expanded the range of their professional skills. Overall, the online course experience improved their professional self-image and enhanced their confidence in their ability to function in cyberspace, which they considered especially important in relation to their role as teachers in the digital age.

\subsubsection{The social aspect of the teachers' role perception as shaped by the online course experience}

In social terms, the teachers referred to their perception of the teacher's role in relation to their collaboration and team work experiences and the significance of the social domain in the teacher's work in the digital era. The teachers especially spoke about the nature of team work and its implementation in their work at school. Participants considered three levels when addressing the social aspect of role perception: the pupils, the teachers, and the school.

The following quotes demonstrate the meanings that teachers attributed to their experience of team work and collaboration during the course and the implications of this work for their professional role.

Teachers' role perception vis-à-vis the pupils:

- 'Team work among pupils offers a variety of different teaching methods and encourages the integration of computers'

- 'Employing collaboration between pupils as a teaching method necessitates the presentation of challenges and demands higher-order thinking'

Teacher's role perception vis-à-vis their colleagues:

- 'Working online with other teachers, as a team, reduces fears, and allows mutual learning'

- 'Collaboration facilitated by ICT is a worthwhile activity that should be practiced regularly among colleagues'

Teacher's role perception vis-à-vis the school:

- 'Collaboration can be used as a tool to motivate change processes in the school'

- 'Team work enables the achievement of better results'

- 'Collaboration can be achieved by working with digital tools'

Thus, for example, one of the teachers noted:

The professional changes that we undergo are created as a result of our experiences and the feedback we are given on the way; sometimes the change is an impetus to become a leading figure in the system. It's important that we internalise these insights and see them as a way of life in the organisation in the professional and administrative roles that we fill as teachers in the school.

\subsubsection{The pedagogic aspect of the teachers' role perception as shaped by the online course experience}

The pedagogic aspect was seen mainly in the teachers' descriptions of how they experienced and experimented with ICT, the ICT pedagogic tools and methods they were exposed to through the online course, and their thoughts about implementing these in their own teaching at school.

The main tools that the teachers acquired and that they reported having used previously in their teaching were: recording and editing films, processing pictures, advanced searches on the Internet, use of Google Drive. They also noted that the course enabled them to develop skills and capabilities to better incorporate these technological tools in their pedagogy and to find and provide learning contents. 
Thus, for example one of the teachers noted: 'I was exposed to tools, contents, technological tools, and pedagogic tools and I was able to integrate these components in my teaching in an informed, balanced, and correct manner'.

The teachers also noted having learned about some of the tools for the first time, namely, the tools for peer evaluation and the PBL approach. For example, one of them remarked: 'The tools for peer evaluation were new and fascinating, relevant to my role as a teacher', while another teacher described the experience thus: 'PBL is a tool that I really believe in. I am happy that I had the opportunity to try this out and so I can apply it in my classroom teaching'.

The research findings revealed that through the course, participants learned to discover what were their personal weaknesses in the field of teaching with technology, which tools they had mastered, and which tools they had yet to master, either partially or fully. Moreover, they became aware of the extent to which they felt confident integrating these tools in their daily work in the classroom.

To recap, three distinct aspects were prominent in participants' descriptions of both their experiences during the course and of the meanings they attributed to experiences that helped shape their perception of their role as teachers in the digital era. Table 1 below summarises the expressions of these aspects in the teachers' testimony.

Table 1: Findngs summary

\begin{tabular}{|c|c|c|}
\hline Aspect & $\begin{array}{l}\text { The Teachers' Experiences in an Online PBL } \\
\text { Course. }\end{array}$ & $\begin{array}{l}\text { The Impact of These Experiences on Teachers' } \\
\text { Role Perception in the Digital Age. }\end{array}$ \\
\hline Personal & $\begin{array}{l}\text { Participants reported a sense of enrichment } \\
\text { and pleasure derived from the learning } \\
\text { experience. }\end{array}$ & $\begin{array}{l}\text { Participants emphasised the acquisition of abilities } \\
\text { and the honing of skills for working in both the } \\
\text { virtual and physical worlds. }\end{array}$ \\
\hline Social & $\begin{array}{l}\text { Participants forged professional } \\
\text { interpersonal relationships and } \\
\text { collaborations with colleagues. }\end{array}$ & $\begin{array}{l}\text { Participants gained an understanding of the } \\
\text { significance of the social domain in the teacher's } \\
\text { work and related to the impact of collaboration on } \\
\text { their role vis-à-vis the pupils, their colleagues, and } \\
\text { the school. }\end{array}$ \\
\hline Pedagogical & $\begin{array}{l}\text { Participants emphasised methods and tools } \\
\text { that helped them as learners to increase } \\
\text { their knowledge and understanding of ICT- } \\
\text { related pedagogic tools and methods. }\end{array}$ & $\begin{array}{l}\text { Participants reported a new awareness of their } \\
\text { strengths and weaknesses in the realm of ICT } \\
\text { pedagogy and their degree of confidence } \\
\text { regarding the integration of said tools in the } \\
\text { classroom. }\end{array}$ \\
\hline
\end{tabular}

In general, the findings indicate that learning in the online format allowed the participating teachers to form insights concerning what constitutes meaningful learning that increases motivation. It also enabled the participants to understand the implications of being a teacher in the digital era and how to adapt teaching to the culture of this era. One of the teachers explained it thus:

This type of learning helped me to gain insights that influenced and will influence my professional development. It is important to continue to learn over your professional career, but it is also important that this should be meaningful, in order to leave its mark ... professional changes that enhance our professional lives occur because of enlightening experiences that we have on the way, and often the very fact of the change is what affords us the insight... as leading figures in the education system and in the school organisation we should internalise these insights and see them as a way of life for the organisation, forming a culture founded on values and perceptions.

The course subject and the way in which it was taught led the participants to insights regarding their future professional development, and regarding observations pertaining to their teaching methods, so that they could improve the existing class and school processes and introduce new teaching processes appropriate for the digital world.

It also emerged that learning about the PBL in an online course helped the teachers develop skills for teaching and learning using collaborative team work alongside personal work. They felt they had been, exposed to a different kind of learning. Thus, studying in this course constituted a model for meaningful learning, while introducing participants to ways to integrate technological means into their routine teaching. It also helped 
develop their teaching skills and acquainted them with the computerised environment. This was explained by one of the teachers.

This type of learning influenced my professional development, since it gave me tools and ideas to integrate within my teaching methods as a teacher. It also allowed me to broaden my horizons concerning computerised learning and technology use in the future.

The research findings indicate that learning in the online course using the PBL approach positively influenced the learning-teaching skills that the participating teachers acquired, creating a positive learning experience. In turn, this experience provided the motivational impetus to face challenges and develop new skills. They gained a fresh perception of learning as a continuous process that stimulates their professional growth and pedagogic development as teachers in the schools.

\section{Discussion and conclusions}

The phenomenon of online learning has been gaining popularity at all levels of the learning sphere, from the school education system to higher education institutions (Khan et al., 2017). Stakeholders involved in the system see this phenomenon as one of the expressions of human development affecting economic, technological, social and cultural aspects of human life (Ching, Hsu and Baldwin, 2017).

The assimilation of technological innovation in the education system constitutes an essential foundation for future advancement and progress in the digital era (Tsybulsky and Levin, 2019). Despite a comprehensive understanding of the importance of assimilating technological innovation in the education system, the assimilation process differs from institution to institution in terms of the path, stages, pace, and even content. The differences stem from a large number of factors that influence the process (Avidov-Ungar and Eshet-Alkalai, 2011a, Avidov-Ungar and Eshet-Alkalai, 2011b, Avidov-Ungar, O and Magen-Nagar, 2014). The purpose of the research described here was to trace the significant learning experiences of practicing teachers enrolled in a Master's degree programme in Education. The aim was to learn how the experience of participating in an online course using the PBL approach influenced the learners' perceptions of their role as teachers in the digital era.

The main finding was that the teachers who participated in the online course took into account personal, pedagogic, and social aspects when describing both their experiences and the significance they attributed to said experiences, in terms of their perceptions of their role as teachers in the digital era. Moreover, the research findings indicate that after studying the online course using the PBL approach, not only were the participants able to hone their perception of the teacher's role in the digital age, but also were able to accommodate this new knowledge within the trajectory of their professional development.

The main contribution of the current study is in shedding light on participants' perceptions of their role as teachers in the digital age. Participation in an online course that featured the PBL approach provided experiences that helped shape their role perception in this regard. The underlying assumption was that the course, its contents, framework, and approach provided unique and novel experiences, which in turn set the stage for a reexamination of their role as teachers in the digital age.

It seems, in this context, that the course that constituted the arena for the present research constitutes an example of a unique platform that could be used to train practicing teachers in the digital era. Relying on the study by Tsybulsky and Levin (2019), it seems that the teachers who participated in the online course were able to learn from their experiences during the course and understood the implications of these experiences for their role as teachers. Thus, they were able to contemplate the subjective, interpersonal, and objective components of becoming "digital citizens" in their professional life.

The research findings regarding the learning experiences that shaped the teachers' perception of their role in the digital age allowed us to track the manner in which personal experiences shape these role-perceptions. A clear picture emerged, indicating that teachers' participation in an experiential learning (Kolb, 1983) process (in this case an online course using the PBL approach) had an impact on teachers' role perception. The teachers' positive impressions of this learning experience included the acquisition of tools and skills as well as positive implications for their professional, pedagogic, and managerial growth. 
On the one hand, this finding supports previous studies in this field, e.g., Tsybulsky, et al., 2020; Tsybulsky and Muchnik-Rozanov, 2019; Tsybulsky and Oz, 2019. However, on the other hand, the present findings are innovative, as they demonstrate the way in which a cycle of experiences is created: experiential learning-shaping of role-perceptions-meanings of educational-managerial practice among learners who were practicing teachers and also held managerial roles in their schools.

It should be noted that the research findings are based on a small sample that was recruited and studied between the years 2014 and 2016. The number of students who participated in this online course each year was relatively small (between 17-19 students). It is recommended that future studies should examine the three aspects of learners' experiences that emerged in the research described herein and continue to explore and identify components of the learning process that can help teachers adapt their role-perceptions to the demands of the digital age.

In conclusion: the personal, pedagogic, and social aspects of the experiential learning were evident in the participants' descriptions and in the meanings they attributed to this experience, which I turn led them to reevaluate their role as teachers in the digital age. Together these aspects constitute a system, one that is influenced by the format of teaching and simultaneously influences the learning experience. Hence, as a process that addresses all three aspects, this experience has also long-term implications for the evolution of participants' personal and professional development and affects their perception of their role as teachers.

\subsection{Practical implications}

The practical implications of the present findings are related to the process of preparing teachers to adapt their role perception to the advantages and demands of the digital era. It seems that in this era, it is necessary to provide the right combination of online learning and experiential learning, such as the online course using the PBL approach described in this article. We suggest that it was more than the course's online format and more than its use of the PBL approach that led to the finding pertaining to adaptation of teachers' role perception. Rather it was this particular combination, which allowed the learners to try out digital experiences while they created significant pedagogic or organisational products for their professional and administrative roles as teachers and members of the school organisation. Clearly teachers need to be presented with opportunities to learn and gain significant experiences in the target context and framework. Through their experiences they can construct their worldview and role perception of what it means to be a teacher in the digital era while experimenting with meaningful learning, including the use of digital tools.

It bears repeating that the research participants were students in a graduate-degree program who were also teaching in schools. The requirement to take an online course as part of the Master's program enabled them to partake in a learning experience that differs from the type of learning experience with which they typically provide their pupils at school. The findings of the current study suggest that the teaching strategies to which the participants were exposed should be adopted as an integral part of teachers' professional development process, throughout the course of their career.

It is recommended that teachers' professional development processes should include learning experiences involving features of digital-era learning, such as team work and collaboration in both virtual and real environments. It is also recommended that lecturers teaching online courses should define them not as external and temporary projects, but rather as an inseparable part of the teaching culture of the digital era. The findings of the current study make it evident that encouraging learners to develop their skills and abilities as digital citizens will be advantageous for the professional and personal development of all parties involved.

\section{References}

Avidov-Ungar, O. and Eshet-Alkalai, Y., 2011a. Teachers in a world of change: teachers' knowledge and attitudes towards the implementation of innovative technologies in schools. Interdisciplinary Journal of E-Learning and Learning Objects, 7(1), pp. 291-303.

Avidov-Ungar, O. and Eshet-Alkalai, Y., 2011b. The Islands of Innovation model: opportunities and threats for effective implementation of technological innovation in the education system. Issues in Informing Science and Information Technology, 8, pp. 363-376.

Avidov-Ungar, O. and Magen-Nagar, N., 2014. Teachers in a changing world: attitudes towards organizational change. Journal of Computers in Education, 1(4), pp. 227-249. 
Baldwin, S., Ching, Y. H. and Hsu, Y. C., 2018. Online course design in higher education: a review of national and state-wide evaluation instruments. TechTrends, 62(1), pp. 46-57.

Barak, M. and Watted, A., 2017. Project-based MOOC: enhancing knowledge construction. In: I. Levin and D. Tsybulsky, eds. Digital tools and solutions for inquiry-based STEM learning. Hershey, PA: IGI Global. pp. 282-307.

Ben-Peretz, M., Mendelson, N. and Kron, F. W., 2003. How teachers in different educational contexts view their roles. Teaching and Teacher Education, 19(2), pp. 277-290.

Brownlee, J. and Berthelsen, D., 2006. Personal epistemology and relational pedagogy in early childhood teacher education programs. Early Years, 26(1), pp. 17-29.

Brownlee, J. and Berthelsen, D., 2008. Developing relational epistemology through relational pedagogy: new ways of thinking about personal epistemology in teacher education. In: M.S. Khine (ed) Knowing, knowledge and beliefs; epistemological studies across diverse cultures Netherlands: Springer. pp. 405-422.

Ching, Y.H., Hsu, Y.C. and Baldwin, S., 2017. Becoming an online teacher: An analysis of prospective online instructors' reflections. In: J. Dron and S. Mishra Eds., Proceedings of E-Learn: World Conference on E-Learning in corporate, government, healthcare, and higher education. Vancouver: Association for the Advancement of Computing in Education AACE, pp. 278-291. Available at: https://www.learntechlib.org/p/181198/ [Accessed 24 December 2017]

Choi, M., Glassman, M. and Cristol, D., 2017. What it means to be a citizen in the internet age: development of a reliable and valid digital citizenship scale. Computers and Education, 10(7), pp. 100-112.

Chu, S. K. W., Reynolds, R. B., Tavares, N. J., Notari, M. and Lee, C. W. Y., 2016. Teachers' professional development. In: S.K.W Chu, R.B. Reynolds, N.J. Tavares, M. Notari and C.W.Y Lee. 21st century skills development through inquiry-based learning; from theory to practice. Singapore: Springer. pp. 109-129.

Creswell, J. W. and Poth, C. N., 2016. Qualitative inquiry and research design: Choosing among five approaches. Thousand Oaks, CA: Sage.

Fives, H. and Buehl, M. M., 2008. What do teachers believe? Developing a framework for examining beliefs about teachers' knowledge and ability. Contemporary Educational Psychology, 33(2), pp. 134-176.

Fives, H. and Buehl, M. M., 2010. Teachers' articulation of beliefs about teaching knowledge: conceptualizing a belief framework. In: L. D. Bendixen and F. C. Feucht (Eds.), Personal epistemology in the classroom: theory, research, and implications for practice pp. 470-515. Cambridge, England: Cambridge University Press.

Floridi, L., 2014. The fourth revolution: how the infosphere is reshaping human reality. Oxford: OUP.

Garrison, D. R., Anderson, T. and Archer, W., 1999. Critical inquiry in a text-based environment: computer conferencing in higher education. The Internet and Higher Education, 2(2-3), pp. 87-105.

Garrison, D. R., Anderson, T. and Archer, W., 2001. Critical thinking, cognitive presence, and computer conferencing in distance education. American Journal of Distance Education, 15(1), pp. 7-23.

Garrison, D. R. and Cleveland-Innes, M., 2005. Facilitating cognitive presence in online learning: interaction is not enough. The American Journal of Distance Education, 19(3), pp. 133-148.

Girvan, C., Conneely, C. and Tangney, B., 2016. Extending experiential learning in teacher professional development. Teaching and Teacher Education, 5(8), pp.129-139.

Häkkinen, P., Järvelä, S., Mäkitalo-Siegl, K., Ahonen, A., Näykki, P. and Valtonen, T., 2017. Preparing teacher-students for twenty-first-century learning practices PREP 21: a framework for enhancing collaborative problem-solving and strategic learning skills. Teachers and Teaching, 23(1), pp. 25-41.

Halliday, M. A. K. and Matthiessen, C. M., 2013. Halliday's introduction to functional grammar. Abingdon: Routledge.

Hill, J. R., Song, L. and West, R. E., 2009. Social learning theory and web-based learning environments: a review of research and discussion of implications. The American Journal of Distance Education, 23(2), pp. 88-103.

Hofer, B. K., 2001. Personal epistemology research: implications for learning and teaching. Educational Psychology Review, 13(4), pp. 353-383.

Hussein-Farraj, R., Barak, M. and Dori, Y., 2012. Lifelong learning at the Technion: graduate Students' perceptions of and experiences in distance learning. Interdisciplinary Journal of E-Learning and Learning Objects, 8(1), pp. 115-135.

Jones, M. G. and Carter, G., 2007. Science teachers' attitudes and beliefs. In: S. K. Abell and N. G. Lederman (eds.) Handbook of research on science education. Mahwah, New Jersey: Lawrence Erlbaum Associates, pp. 1067-1104.

Khan, A., Egbue, O., Palkie, B. and Madden, J., 2017. Active Learning: engaging students to maximize ILearning in an online course. Electronic Journal of e-Learning, 15(2), pp. 107-115.

Kleen, B. and Soule, L., 2010. Reflections on online course design-Quality matters ${ }^{\mathrm{TM}}$ evaluation and student feedback: an exploratory study. Issues in Information Systems, 11(2), pp. 152-161.

Kolb, A. Y. and Kolb, D. A., 2005. Learning styles and learning spaces: enhancing experiential learning in higher education. Academy of Management Learning and Education, 4(2), pp.193-212.

Kolb, D.A., 1983. Experiential learning: experience as the source of learning and development. Englewood Cliffs, $\mathrm{NJ}$ : Prentice-Hall.

Levin, I. and Tsybulsky D., 2017. The constructionist learning approach in the digital age. Creative Education, 8(15), pp. 2463-2475.

Luft, J. A. and Roehrig, G. H., 2007. Capturing science teachers' epistemological beliefs: the development of the teacher beliefs interview. Electronic Journal of Science Education, 11(2), pp. 38-63.

Majeski, R. A., Stover, M. and Valais, T., 2018. The community of inquiry and emotional presence. Adult Learning, 29(2), pp. 53-61. 
Marra, R., 2005. Teacher beliefs: the impact of the design of constructivist learning environments on instructor epistemologies. Learning Environments Research, 8(2), pp. 135-155.

Mason, J., 2010. Mathematics education: theory, practice and memories over 50 years. For the Learning of Mathematics, 30(3), pp. 3-9.

Moustakas, C.,1994. Phenomenological research methods. London: Sage publications.

Naresha, B., Reddyb, D. B. S. and Pricildac, U., 2016. A study on the relationship between demographic factor and elearning readiness among students in higher education. Global Management Review, 10(4), pp. 1-11.

$\mathrm{Ni}, \mathrm{A}$. Y., 2013. Comparing the effectiveness of classroom and online learning: teaching research methods. Journal of Public Affairs Education, 19(2), pp. 199-215.

Parkes, M., Stein, S. and Reading, C., 2015. Student preparedness for university e-learning environments. The Internet and Higher Education, 25 (April), pp. 1-10.

Prensky, M., 2009. H. sapiens digital: from digital immigrants and digital natives to digital wisdom. Innovate: Journal of online education, 5(3). Available at: https://www.learntechlib.org/p/104264/ [Accessed April 18, 2020]

Prestridge, S., 2017. Examining the shaping of teachers' pedagogical orientation for the use of technology. Technology, Pedagogy and Education, 26(4),pp. 1-15.

Stahl, E. and Bromme, R., 2007. The CAEB: an instrument for measuring connotative aspects of epistemological beliefs. Learning and Instruction, 17(6), pp.773-785.

Sung, E. and Mayer, R. E., 2012. Five facets of social presence in online distance education. Computers in Human Behavior, 28(5), pp. 1738-1747.

Taradi, S. K., Taradi, M., Radić, K. and Pokrajac, N., 2005. Blending problem-based learning with web technology positively impacts student learning outcomes in acid-base physiology. Advances in Physiology Education, 29(1), pp. 35-39.

Tsybulsky, D., Gateneo-Kalush, M., Abuganem, M. and Grobgeld, E., 2020. Experiences of preservice teachers exposed to project-based learning. European Journal of Teacher Education. https://doi.org/10.1080/02619768.2019.1711052

Tsybulsky, D. and Levin, I., 2019. Science teachers' worldviews in the age of the digital revolution: structural and content analysis. Teaching and Teacher Education, 86(November), p.102921 https://doi.org/10.1016/j.tate.2019.102921

Tsybulsky, D. and Muchnik-Rozanov, Y., 2019. The development of student-teachers' professional identity while teamteaching science classes using a project-based learning approach: a multi-level analysis. Teaching and Teacher Education, 79(March), pp. 48-59.

Tsybulsky, D. \& Muchnik-Rozanov, Y. 2021. Worldviews of science teachers in educational-technological context as a key factor in digitalization of teaching practices. Israel Science Foundation Gateway, F1000Research. https://doi.org/10.12688/f1000research.28074.3

Tsybulsky, D. and Oz, A., 2019. From frustration to insights: experiences, attitudes and pedagogical practices of pre-service science teachers implementing PBL in elementary school. Journal of Science Teacher Education, 30(3), pp.259-279.

van Manen, M., 1990. Researching lived experience. Human science for an action sensitive pedagogy. Ontario, Canada: The University of Western Ontario.

van Manen, M., 2014. Phenomenology of practice: meaning-giving methods in phenomenological research and writing. Walnut Creek, CA: Left Coast Press.

Xiao, J. and Wilkins, S., 2015. The effect of lecturer commitment on student perception of teaching quality and student satisfaction in Chinese higher education. Journal of Higher Education Policy and Management, 37(1), pp. 98-110. 